\title{
Influência de essências na alimentação artificial energética na atratividade de Abelhas Apis mellifera
}

\section{Influence of essences in energy artificial food the bees attractiveness Apis mellifera}

\author{
Isidro Patrício de Almeida Neto ${ }^{{ }^{*}}$, Rosilene Agra da Silva ${ }^{3}$, Saulo Soares da Silva ${ }^{3}$, José da Silva Sousa ${ }^{4}$, Anderson Bruno
} Anacleto de Andrade ${ }^{5}$

\begin{abstract}
Resumo: O objetivo desse trabalho foi avaliar a atratividade de diferentes aromas adicionados a alimentação artificial energética de abelhas Apis mellifera. O delineamento experimental usado foi DIC no qual constou de 11 tratamentos e quatro repetições, sendo os tratamentos os aromas tutti-frutte, erva-doce, maracujá, café, baunilha, morango, amarula, menta, cereja, coco e testemunha (sem aroma) e as repetições foram considerados os dias de coleta de dados. Foram feitas observações do fluxo de abelhas a cada cinco minutos fazendo o registro fotográfico para contagem das mesmas. O período de observação ao longo do dia foi de 20 minutos sendo realizado no horário da manhã. Observamos que no decorrer do trabalho o fluxo das abelhas foi aumentando gradativamente em todas as essências a cada repetição sendo que essência que mais atraiu as abelhas foi a amarula (em media 147 abelhas), não deferindo da essência da baunilha, porém a baunilha não diferiu das demais essências.
\end{abstract}

Palavras-chave: Alimento artificial; Essências; Abelhas; Escassez.

Abstract: The aim of this study was to evaluate the attractiveness of Apis mellifera by energy added artificial feeding of different aromas. The experimental design used was DIC in which consisted of 11 treatments and four replications, and the treatments the tutti-frutte aromas, fennel, passion fruit, coffee, vanilla, strawberry, amarula, mint, cherry, coconut and control (without aroma) and repetitions were considered the days of data collection. Observations of bees stream samples were collected every five minutes making the photographic record to count them. The observation period throughout the day was 20 minutes being held in the morning hours. We note that during the work flow of bees has been increasing gradually in all essences with each repetition being that essence that attracted the bees was amarula (on average 147 bees), not deferring the essence of vanilla, but vanilla did not differ the other essences.

Key words: Artificial food; Essences; Bees; Scarcity.

\footnotetext{
*Autor para correspondência

Recebido para publicação em 27/04/2015; aprovado em 20/05/2015

${ }^{1}$ Mestrando em Sistemas Agroindustriais, Universidade Federal de Campina Grande, Pombal, (83)999006665; E-mail: isidroneto2@gmail.com

${ }^{2}$ Professora Doutora, Unidade Acadêmica de Ciências Agrárias da Universidade Federal de Campina Grande (UFCG). E-mail: rosilene@ ccta.ufcg.edu.br;

${ }^{3}$ Mestrando em Sistemas Agroindustriais, Universidade Federal de Campina Grande, Pombal, (83)999083364, E-mail: saulosoares90@ gmail.com;

${ }^{4}$ Mestre em Sistemas Agroindustriais, Universidade Federal de Campina Grande, E-mail: silva_agronomo@hotmail.com

${ }^{5}$ Aluno de Graduação em Agronomia, UFCG/CCTA, Pombal-PB; E-mail: bdeandrade3@gmail.com
} 


\section{INTRODUÇÃO}

O Brasil é um dos poucos países com um grande potencial apícola, apresentando uma gama de produtos fabricados pelas abelhas, dentre eles se destaca o mel, pólen, própolis, cera, apitoxina e geleia real. Nosso país tem o privilegio de realizar várias coletas de mel, o que coloca a apicultura brasileira entre as mais competitivas do mundo, isto devido à resistência a pragas e doenças que tantos prejuízos têm causado em outras importantes regiões apícolas mundiais (BERTOLDI et al, 2004).

Em condições favoráveis as abelhas vão à busca de armazenar alimentos para atravessarem o período de escassez, onde a falta de néctar e pólen afetará o desenvolvimento do enxame, podendo ocorrer à diminuição das suas atividades na ausência da florada, logo, quando a reserva de alimento na colônia é insuficiente é aconselhável o fornecimento de alimentação artificial às abelhas (WIESE, 1986).

Ocorrendo a redução da postura da rainha e um desequilíbrio da população na colmeia, dependendo da região, os períodos de floradas poderão ser maiores ou menores, bem distribuídos ou não, podendo ocorrer períodos de completa ausência de alimento no campo necessitando assim complementar a dieta com um alimento rico em proteínas e energético como é o pólen e o xarope de açúcar (PORTELA; GALLEGO, 1999). Em tais circunstâncias, é essencial a interferência do apicultor sendo importante que o conhecimento da sequência de ocorrência das floradas de sua região e que o mesmo saiba avaliar a existência ou não da disponibilidade de alimento para as abelhas durante todo o ano.

A necessidade de o apicultor dispor de um alimento com um bom aroma para ser usado em qualquer época do ano e que seja coletado em quantidade pelas abelhas, faz com que ele busque novas alternativas na expectativa de encontrar uma solução para esse problema suprem o valor nutritivo do pólen. Segundo Herbert e Shimanuki (1978), quando as abelhas têm uma livre escolha entre o pólen e o substituto, elas geralmente têm maior preferência pelo primeiro.

Sob o risco de perda de enxames ou enfraquecimento geral das colônias muitas dietas oferecidas às abelhas não levam em consideração a atratividade pelas abelhas, logo, a influência que o aroma possui para atrair as abelhas na alimentação é um aspecto importante a ser avaliados.

Portanto, o objetivo deste trabalho foi avaliar a atratividade de diferentes aromas artificiais adicionados a alimentação artificial energética de abelhas Apis mellifera, contribuindo para um maior estimulo ao consumo desta alimentação para a manutenção do desenvolvimento da população nos enxame.

\section{MATERIAL E MÉTODOS}

O trabalho foi desenvolvido no apiário instalado numa propriedade vizinha ao campus da Universidade Federal de Campina Grande, no município de Pombal - PB (Figura 1) no período de 20 a 24 de outubro de 2010. O apiário foi composto por oito colmeias populosas de abelhas Apis mellifera.
Figura 1. Mapa de localização do Município de Pombal, Paraíba.

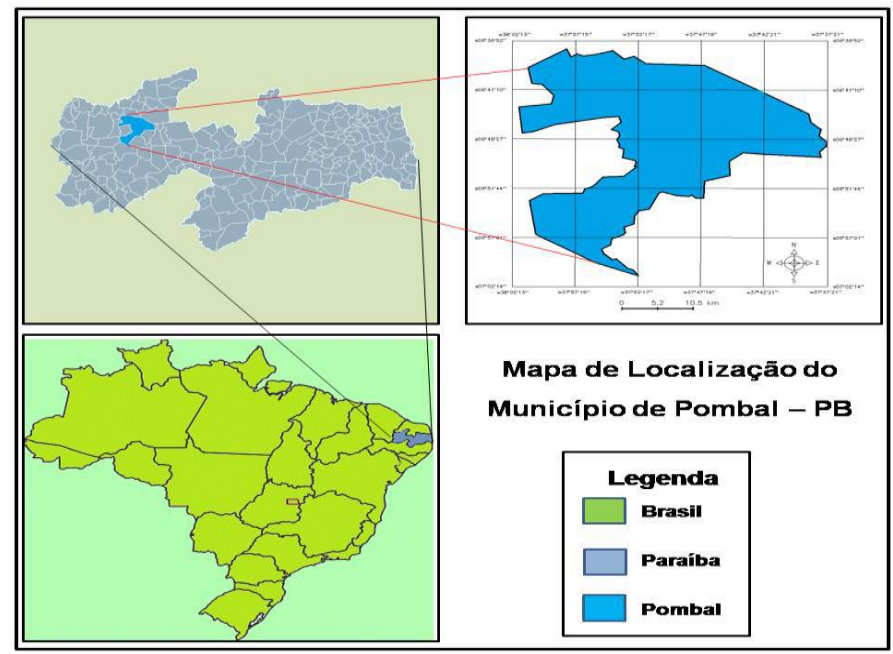

O delineamento experimental constou de 11 tratamentos e quatro repetições, sendo os tratamentos os aromas tuttifrutte, erva-doce, maracujá, café, baunilha, morango, amarula, menta, cereja, coco e testemunha (sem aroma) e as repetições foram considerados os dias de coleta de dados (Figura 2).

Figura 2. Disposição das bandejas com a alimentação artificial, Pombal, Paraíba

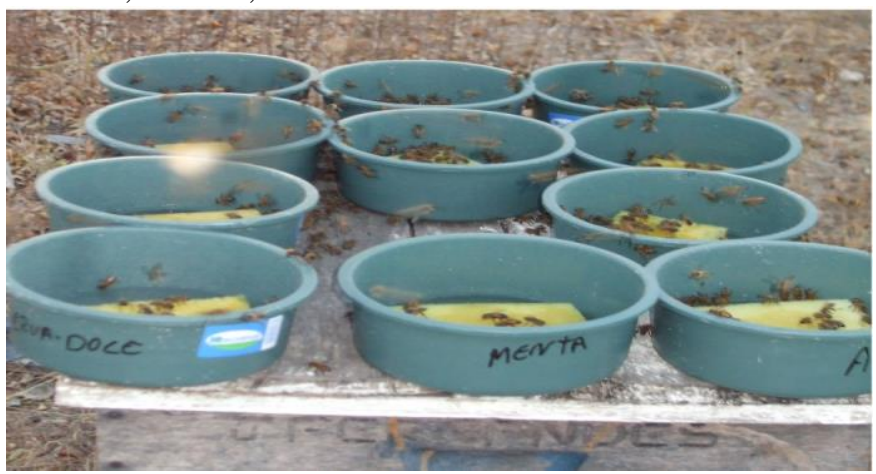

O xarope de açúcar foi elaborado nas proporções de $50 \%$ (cinquenta por cento) de açúcar e $50 \%$ (cinquenta por cento) de água sendo a essência adicionada na dose recomendada pelo fabricante $(0,001 \%)$. A testemunha não foi adicionado o aroma artificial. $\mathrm{O}$ alimento foi colocado em um recipiente plástico contendo uma esponja para evitar que as abelhas não se afogassem essa técnica utilizada é denominada de alimentador coletivo (Figura 3).

Foi montada uma bancada de madeira no qual foi colocado sobre ela os recipientes contendo os alimentos artificiais energéticos. Foram feitas observações do fluxo de abelhas a cada cinco minutos fazendo o registro fotográfico para contagem das mesmas. O período de observação ao longo do dia foi de 20 minutos sendo realizado no horário da manhã, por volta das 8:00 horas, período este de maior atividade das abelhas na coleta de alimento (Figura 3). 
Figura 3. Adição do xarope de açúcar com as essências na alimentação. Pombal, Paraíba
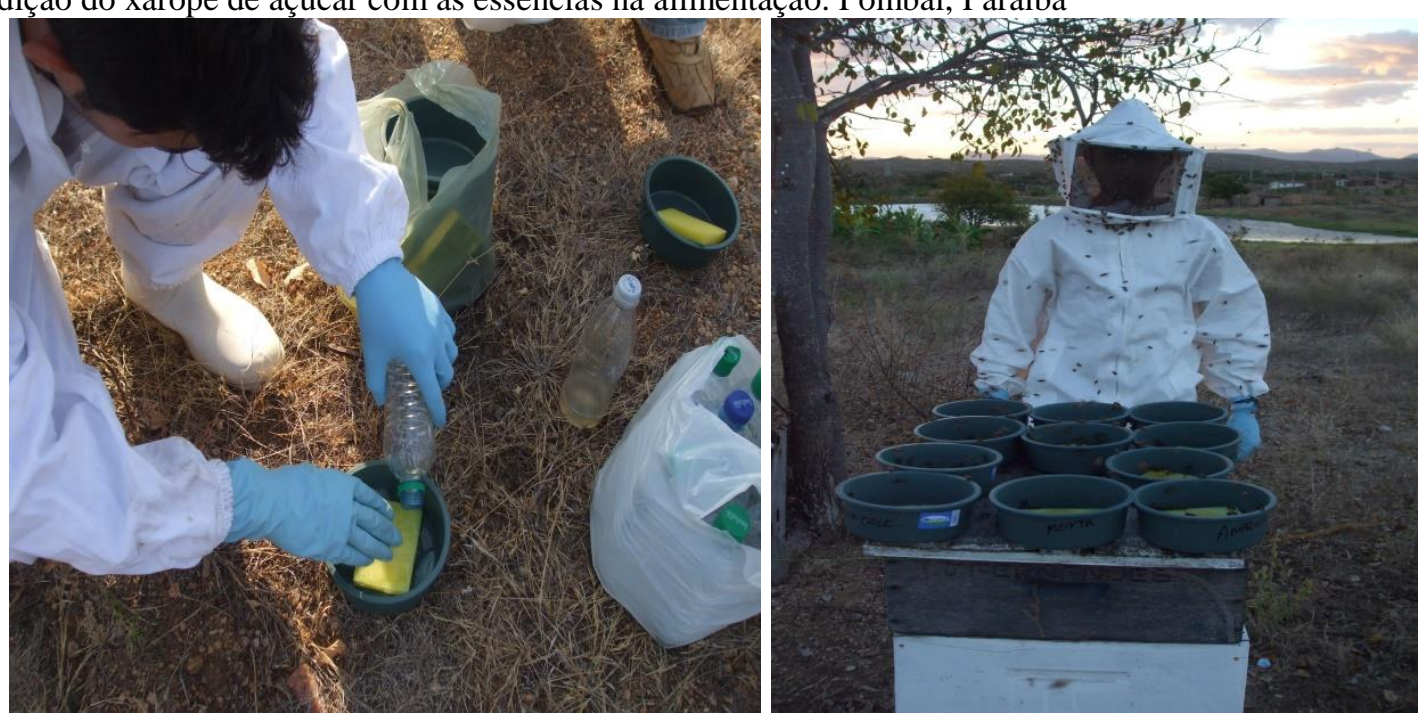

Os dados foram tabulados em planilha do Excel e submetidos ao análise estatística utilizando-se o programa estatístico ESTAT (KRONKA; BANZATO, 1995). Utilizouse o teste de Tukey ao nível de $5 \%$ de probabilidade para se fazerem as comparações entre os aromas testados.

\section{RESULTADOS E DISCUSSÃO}

Na Tabela 1 encontram-se os valores totais de cada repetição e os valores médios de cada tratamento do teste de frequência de abelhas na alimentação artificial energética adicionada de essências artificiais comerciais, onde verificouse a essência mais atrativa para as abelhas (Apis mellifera).

Tabela 1. Valores totais e médios de abelhas frequentes no teste de atratividade de abelhas (Apis mellifera) à alimentação energética com suas respectivas essências artificial testada. Pombal, Paraíba

\begin{tabular}{|c|c|c|c|c|c|}
\hline \multirow{2}{*}{$\begin{array}{l}\text { Tratamentos } \\
\text { (Essências) }\end{array}$} & \multicolumn{4}{|c|}{ Dias de observação (repetições) } & \multirow{2}{*}{ Média } \\
\hline & 21/10/2010 & $22 / 10 / 2010$ & $23 / 10 / 2010$ & $24 / 10 / 2010$ & \\
\hline Testemunha & 30 & 21 & 18 & 32 & 24B \\
\hline Tutti-frute & 18 & 50 & 18 & 65 & $38 \mathrm{~B}$ \\
\hline Erva-doce & 04 & 08 & 13 & 59 & 21B \\
\hline Maracujá & 31 & 17 & 42 & 48 & $35 \mathrm{~B}$ \\
\hline Cereja & 14 & 24 & 17 & 43 & $25 \mathrm{~B}$ \\
\hline Baunilha & 58 & 63 & 49 & 76 & $62 \mathrm{~B}$ \\
\hline Coco & 42 & 24 & 06 & 75 & 38B \\
\hline Café & 54 & 22 & 20 & 41 & $34 \mathrm{~B}$ \\
\hline Morango & 13 & 32 & 42 & 48 & $34 \mathrm{~B}$ \\
\hline Menta & 07 & 07 & 40 & 12 & 17B \\
\hline Amarula & 40 & 192 & 48 & 307 & $147 \mathrm{~A}$ \\
\hline
\end{tabular}

Médias seguidas de mesma letra na coluna não diferem estatisticamente entre si pelo teste de Tukey $(5 \%)$. CV = 98.39

Podemos observar que a essência que mais atraiu abelhas foi a amarula (em média 147 abelhas), não diferindo estatisticamente ao nível de $5 \%$ pelo teste e Tukey da essência baunilha, porém diferiu das demais essências.

Segundo Couto (1998), a finalidade de aumentar a aceitabilidade do alimento pelas abelhas africanizadas, no entanto, a maior importância do néctar para as abelhas reside em fornecer praticamente todos os glicídios ou carboidratos (açúcares), responsáveis pela fonte energética da dieta e a produção de mel. Como a apicultura depende exclusivamente dos recursos naturais e pode sofrer declínio de produção no período de entre safra, ou seja, com redução da florada, as modificações na natureza diminuem e acabam destruindo certas plantas utilizadas pelas abelhas, com isso as colônias tem sua produção diminuída ou até mesmo cessada pela falta de alimento e consequentemente o abandono de colmeias. Logo, o presente trabalho mostrou que alguns aromas têm forte influencia na alimentação artificial das abelhas Apis mellífera, fazendo com que haja uma maior aceitação pelo xarope de açúcar.

Esses alimentos alternativos são fornecidos antecipadamente nos favos, para que as abelhas nutrizes do ninho vão se acostumando com o odor estranho dos alimentos quando o mesmo é oferecido em forma liquida (HAYDAK 1970). Vários parâmetros têm sido usados para identificar o alimento mais eficaz, devendo analisar entre outros fatores consumo do alimento, aumento das concentrações das essências encontradas nos alimentos alternativos, vários autores discutem os parâmetros para estabelecer o seu nicho trófico e por isso, como agentes determinantes de atração alimentar (REAL; RATHCKE, 1991).

$\mathrm{Na}$ presente pesquisa, como foi dito anteriormente, o aroma mais atrativo foi a amarula (Sclerocarya birrea), a qual é extraída de uma árvore de tamanho mediano, originária do 
bioma das savanas da África do Sul e da região da África oriental, caracteriza-se por um tronco único acinzentado e uma copa de folhas verdes, podendo atingir cerca de 10 metros de altura em baixas altitudes, carrega o misticismo de não ser plantada pelos homens e de ter propriedades afrodisíacas. Seu fruto oval é rico em vitamina $C$ que, uma vez fora do pé, começa a fermentar, proporcionando um sabor adocicado e levemente alcoólico.

De acordo com Wiston (2003), as três castas de abelhas têm necessidades nutricionais e mecanismo de alimentação um pouco diferente para satisfazerem suas necessidades, com também, a larva e o adulto de cada casta. Mais os materiais básicos para cria, abelhas adultas, sejam elas operárias, rainhas ou zangões, são os mesmos: néctar e pólen. Esses dois produtos florais provêm à comida necessária para o crescimento larval, a metamorfose e o desenvolvimento do adulto e suas atividades. O néctar provê, basicamente, carboidratos, na forma de açucares, e o pólen, proteínas, lipídios, vitaminas e minerais. As abelhas desenvolveram vários mecanismo para processar o néctar e o pólen, de forma que a comida fornecida em cada fase e a cada casta é a ideal para suas necessidades.

Observamos ainda no decorrer do trabalho que o fluxo das abelhas foi aumentando gradativamente em todas as essências a cada repetição e também, a frequência das abelhas foi aumentando ao longo do horário de observação, o que demonstra a grande importância do aroma dos alimentos desenvolvidos para atrair as abelhas (Figura 4).

Figura 4. Aumento da frequência de visita das abelhas aos alimentadores coletivos com as essências testadas no teste de atratividade ao xarope de açúcar. Pombal, Paraíba.

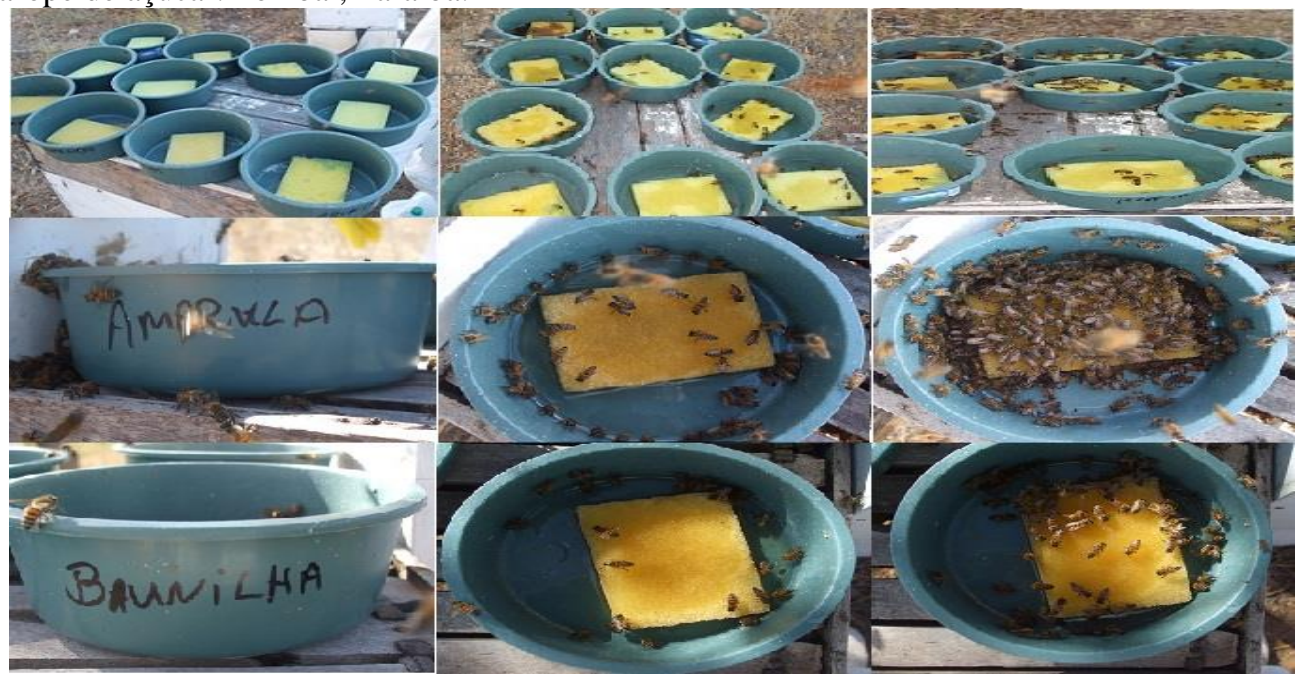

Vários parâmetros tem sido usados para identificar o alimento mais eficaz, devendo analisar entre outros fatores consumo do alimento, aumento de peso das colônias, longevidade das operárias. As características dos alimentos tem que estar de acordo com o sabor agradável, a consistência, a facilidade do preparo e o custo baixo (MILLS,1981). No entanto, a maior importância do néctar para as abelhas reside em fornecer praticamente todos os glicídios ou carboidratos (açúcares), responsáveis pela fonte energética da dieta e a produção de mel (COUTO, 1998). A quantidade, a concentração e o teor de açúcares encontrados no néctar, dão parâmetros para estabelecer o seu nicho trófico e por isso, são discutidos por vários autores como agentes determinantes de atração alimentar (REAL E RATHCKE, 1991).

O néctar floral é uma secreção aquosa da planta que contém de $5 \%$ a $80 \%$ de açúcar e quantidades de compostos nitrogenados, minerais, ácidos orgânicos, vitaminas, lipídeos, pigmentos e substâncias aromáticas (Winston 2003). Dessas últimas substâncias, só o ácido ascórbico (vitamina C) é encontrado, em quantidade apreciável, no néctar; o teor de proteína no mel é, normalmente, menor que 0,2\% (WHITE; RUDYJ, 1978). Sacarose, glicose e frutose são os principais açucares encontrado no néctar. Além desses três açucares, $\alpha$ metil-glucosídio, maltose e trealose e melezitose têm valor nutritivo para as abelhas. A maioria dos outros açucares não tem sabor doce nem valor nutritivo. Alguns açucares, como manose, galactose e ramnose, ou são tóxicos para as abelhas ou causam a redução de sua longevidade (VON FRISCH, 1934, 1965).

Uma larva de operaria necessita de, aproximadamente, $142 \mathrm{mg}$ de mel para seu desenvolvimento, e as exigências anuais de mel para uma colônia foram calculadas em, aproximadamente, 60 a 80kg (WEIPPLE, 1928; ROSOV, 1944; SEELEY, 1985a). De larvas de operarias malalimentadas nascem adultos anões, e a falha do desenvolvimento é alta, se for fornecida menos que $65 \%$ da quantidade normal de comida. As más alimentações de adultos anões resultantes podem ocorrer, quando néctar e pólen estão escassos as colônias estão doentes, a cria começa a ser desenvolvidas muito cedo da primavera ou as colônias têm baixa população de operárias, fatores todos que reduzem a quantidade ou qualidade da comida de cria (JAY, 1964).

$\mathrm{O}$ néctar ou mel, ingeridos pelas operárias, provêem açucares para energia; a maior parte da energia requerida pelas operárias adultas é obtida consumindo mel dos alvéolos, embora néctar e mel possam ser trocados entre operárias. A quantidade de açúcar exigido pelas operárias depende do nível de atividade; a operária em repouso $(A$. m. ligústica) precisa de apenas $0,7 \mathrm{mg} / \mathrm{h}$ de açúcar, quando em voo ela requer 11,5mg/h (OLAERTS, 1956; HEINRICH, 1979). como mencionado a cima, as abelhas utilizam só uns açucares e obtêm deles diferentes quantidades de energia. Os zangões mais velhos se alimentam exclusivamente de mel no favo que lhes fornecem energia necessária para os vôos de acasalamentos. Um zangão em repouso requer só 1 (um) a 3 
(três) $\mathrm{mg} / \mathrm{h}$ de açúcar e quando em vôo consome 14 (quatorze) $\mathrm{mg} / \mathrm{h}$, (MINDT, 1962), uma pouco mais que as operárias. As rainhas são alimentadas pelas operárias com idade em que produzem comidas de cria e, presumivelmente, recebem principalmente comida de cria possivelmente um pouco de mel (ALLEN, 1955, 1960; HAYDAK, 1970).

No entanto, a maior importância do néctar para as abelhas reside em fornecer praticamente todos os glicídios ou carboidratos (açúcares), responsáveis pela fonte energética da dieta e a produção de mel (COUTO, 1998). A quantidade, a concentração e o teor de açúcares encontrados no néctar, dão parâmetros para estabelecer o seu nicho trófico e por isso, são discutidos por vários autores como agentes determinantes de atração alimentar (REAL; RATHCKE, 1991). Mas, apesar da diversidade da flora apícola e da alta concentração de alimento existente no período chuvoso, durante a estação seca, ocorre uma escassez de pasto apícola e, consequentemente, de alimento para as abelhas (PEREIRA et al. 2006). Logo, se faz necessário o uso de alimentação artificial, seja ela energética e/ou proteica, para manutenção dos enxames, mesmo que isto eleve os custos devido à aquisição do açúcar no preparo do xarope e mão-de-obra extra.

Outro ponto importante a ser observado é no que se refere à toxicidade que muitas vezes é desprezada como relata Pereira et al. (2002) e os apicultores utilizam por conta própria rapadura de cana-de açúcar, xarope de água e açúcar, farelo de soja, achocolatado em pó, farinha láctea, ração de postura para galinha, sucedâneo de leite para bezerros e ração de codorna e muitas vezes não analisando a toxicidade dos alimentos. Estudando o efeito tóxico de alimentos alternativos para abelhas Apis mellifera, a alimentação energética para as abelhas constitui bem menos problema do que a proteica, haja vista que uma simples mistura de água e açúcar (sacarose).

\section{CONCLUSÕES}

A essência que teve maior atratividade das abelhas Apis mellífera foi a amarula, não diferiu a com a baunilha, porém a baunilha não diferiu com as demais essências;

A essência de amarula é indicada para mistura na dieta artificial de abelhas Apis mellífera.

\section{REFERÊNCIAS BIBLIOGRÁFICAS}

ALLEN M. D. 1955. Observations of honeybees attending their queen. Brit J Anim Behav 3:66-69.

BERTOLDI, F.C. GONZAGA, L. REIS, V.D.A. Características físico-químicas do mel de abelhas africanizadas (Apis mellifera scutellata), com florada predominante de hortelã-do-campo (Hyptis crenata) produzida no Pantanal. IV Simpósio sobre Recursos Naturais e Sócio-Econômicos do Pantanal. Corumbá/MS, 23 a 26 nov, 2004.

BRASIL, Ministério da Agricultura, Pecuária e Abastecimento. Regulamento Técnico de Identidade e Qualidade do Mel. Instrução Normativa 11, de 20 de outubro de 2000 .
CREMONEZ, T.M. Influência da nutrição sobre aspectos da fisiologia e nutrição de abelhas Apis mellifera. Tese(Doutorado). Universidade de São Paulo, Ribeirão Preto. 2001.87p.

Haydak, M. H. Honey bee nutrition. Ann Rev Entomol 15:143-156,(1970).

JAY, S.C. Starvation studies of larval honey bees. J. Zool. 42: 455-462. Ovary developmente of worker honeybees in colonies without queens. Can. J Zool. 48:169-173, 1964.

KOMATSU, S.S. MARCHINI, L. C. MORETI, A.C.C.C. Análises físico-químicas de amostras de méis de flores silvestres, de eucalipto e de laranjeira, produzidos por Apis mellifera L. 1758 (Hymenoptera;Apidae) no estado de São Paulo.2.Conteúdo de açúcares e de Proteína. Ciência e Tecnologia de Álimentos, Campinas, v.22,n.2,p.143-146, maio-ago,2002.

KRONKA, S.N.; BANZATO, D.A. Estat: sistema para análise estatística versão 2. 3. ed. Jaboticabal: Funep, 243 p. 1995.

MILLS, J. A. Alimentacion de las abejas:um importante metodo de mantenimiento para desarrolar colonias fuertes. Apiacta XVI, Romênia, v.3, p.116-118, 1981.

MINDT, B. Untersuchungen liber das Leben der Drohnen, insbersondere Eenahrung und Geschlechtsreife. Z Bienenforsch. 6: 9-33. 1962.

OLAERTS, E. Der Stoffwechsel der Bienen in Beziehung zu derem Aktivitat und Temperatur. Ber. Int. Bienenz. Kongr. Wien. 16: 70. 1956.

PEREIRA, F. M. Gargalos tecnológicos. In: VILELA, S.L.O.; PEREIRA, F.M. Cadeia produtiva do mel no Rio Grande do Norte. Natal, Sebrae - RN; Teresina: Embrapa Meio-Norte,p.66-92. 2002.

PEREIRA, F.M. FREITAS, B.M. VIEIRA NETO, J.M. LOPES, M.T.R. BARBOSA, A.L. CAMARGO, R.C.R. Desenvolvimento de colônias de abelhas com diferentes alimentos protéicos. Pesquisa Agropecuária Brasileira, Brasília, v.41, n.1, p.1-7, 2006.

PORTELA,E.M.R.,GALLEGO,J.C.S. Alimentación de las abejas: Aplicación práctica de los fundamentos fisiológicos de la nutrición. Portada y gráficos: Elena M. Roblas Portela, 1999.195p.

REAL, L.; RATHCKE,B. J. Individual variation in néctar production and its effect on fitness in Kalmia latifolia. Ecology, v.72, n.1, p.149-155,1991.

SEBRAE. Introduzida no Brasil em 1839, atividade passou por vários problemas até se tornar boa opção aos agricultores brasileiros. Disponível em: http://www.sebrae.com.br/sites/PortalSebrae/artigos/Co nheça o histórico-da-apicultura-no-Brasil. Consultado em: Janeiro de 2015. 
SOUSA, D.C. Importância socioeconômica da Apicultura: manual do agente de desenvolvimento rural. Brasília: Sebrae, Cap. 4. p. 35-41, 2004.

VON FRISCH, K. Uber den Geschmackssinn der Pienen. Z. vergl. Physiol. 21: 1-156. Tanzsprache und Orientierung der Bienen. Berlin, Springer-Verlag. 1965.

WEIPPLE, T. Futterverbrauch und Arbeitsleistung eines Bienenvolkes im Laufe eines. Jahres. Arch.Bienenk. 9:70-79. 1928.
WHITE, J. W, Jr., and O. N. Rudyj. The protein content of horney. J. Apic. Res. 17: 234-238. 1978.

WIESE, H. (Coord.). Nova apicultura. 7.ed. Porto Alegre: Agropecuária, 1986. 493p.

WINStOn, N. L. A Biologia da Abelha. Porto Alegre: Magister, P. 276. 2003. 